\title{
FAKTOR YANG MEMPENGARUHI SERANGAN JANTUNG BERULANG PADA PASIEN AMI DI RUANG ICVCU RSUD Dr. MOEWARDI TAHUN 2016
}

\author{
Fransisca Saktiningtyastuti, Sri Lestari Dwi Astuti \\ Kementerian Kesehatan Politeknik Kesehatan Surakarta Jurusan Keperawatan
}

\begin{abstract}
Consumed Cholesterol Foods, Hypertension, Smoked, Diabetes Mellitus, Exercise, Sleep Quality, Recurrent Heart Attack. Smoking, consuming cholesterol foods, and staying up all night are easy to find in around us. Moreover, some of people that have historic of heart disease, hypertension, or diabetes mellitus haven't pay attention with their lifestyle. Eventhough, consumed cholesterol foods, hypertension, smoked, diabetes mellitus, exercise and sleep quality are can affected recurrent heart attack of patients with acute myocardial infarction in ICVCU Dr.Moewardi hospital in Surakarta. Design of this research is a descriptive analytic with cross sectional approach. The sampling method is total sampling. Analysis of data used chi square, fisher and regression logistic. The result of research obtained factors that affected recurrent heart attack of patients with acute myocardial infarction is consumed cholesterol foods $(p=0,039)$, hypertension $(p=0,014)$, smoked $(p=0,038)$, diabetes mellitus $(p=$ $0,014)$, exercise $(p=0,014)$, and sleep quality $(p=0,014)$. Hypertension and exercise are the greatest influence $(O R=0,065)$, next consumed cholesterol foods $(O R=0,052)$, and diabetes mellitus $(O R=0,035)$. Conclusion: Dominant factors that affected recurrent heart attack of patients with acuce myocardial infarction are hypertension and exercise.
\end{abstract}

\section{Keywords : Consumed Cholesterol Foods, Hypertension, Smoked, Diabetes Mellitus, Exercise, Sleep Quality, Recurrent Heart Attack}

\begin{abstract}
Abstrak: Kolesterol, Hipertensi, Merokok, Diabetes Mellitus, Latihan Fisik, Kualitas Tidur, Serangan Berulang AMI. Kebiasaan merokok, makan makanan kolesterol, begadang sangat mudah kita jumpai disekitar kita. Bahkan, beberapa orang yang sudah memiliki riwayat penyakit jantung, hipertensi, ataupun diabetes mellitus tidak memperhatikan pola hidup mereka. Padahal, konsumsi makanan kolesterol, hipertensi, merokok, diabetes mellitus, latihan fisik dan kualitas tidur dapat menjadi faktor serangan berulang penyakit AMI. Maka, penelitian ini akan menganalisis faktor yang mempengaruhi serangan berulang pada pasien AMI di ruang ICVCU RSUD Dr.Moewardi Surakarta. Desain penelitian ini adalah deskriptif analitik dengan pendekatan cross sectional. Teknik pengambilan sampel menggunakan total sampel dengan jumlah 26 responden. Analisis data menggunakan chi square, uji fisher dan regression logistic. Hasil Penelitian adalah faktor yang berpengaruh terhadap serangan jantung berulang AMI yaitu konsumsi makanan kolesterol $(p=0,039)$, hipertensi $(p=0,014)$, merokok $(p=0,038)$, diabetes mellitus $(p=0,014)$, latihan fisik $(p=0,014)$, dan kualitas tidur $(p=0,014)$. Hipertensi dan latihan fisik mempunyai pengaruh terbesar $(\mathrm{OR}=0,065)$, selanjutnya adalah konsumsi makanan kolesterol $(\mathrm{OR}=0,052)$, dan diabetes
\end{abstract}


mellitus $(\mathrm{OR}=0,035)$. Kesimpulan bahwa faktor dominan yang memepengaruhi serangan jantung berulang AMI adalah hipertensi dan latihan fisik.

Kata Kunci : Kolesterol, Hipertensi, Merokok, Diabetes Mellitus, Latihan Fisik, Kualitas Tidur, Serangan Berulang AMI

\section{PENDAHULUAN}

Pembangunan di negara-negara maju dan berkembang semakin pesat yang berpengaruh terhadap perubahan gaya hidup masyarakat berkaitan dengan kemajuan sosial ekonomi masyarakat kemudian menyebabkan transisi epidemiologi penyakit berkembang di dunia, termasuk salah satunya di Indonesia. Di Indonesia transisi epidemiologi menyebabkan terjadinya pergeseran pola penyakit, dimana penyakit kronis degeneratif sudah terjadi peningkatan. Proporsi kematian penyakit infeksi menurun secara signifikan, namun proporsi kematian karena penyakit degeneratif salah satunya penyakit jantung meningkat.

Pergeseran pola penyakit dibuktikan dengan data statistik laporan World Health Statistic 2010, penyakit tidak menular merupakan penyebab utama 58 juta kematian di dunia dan prosentase penyakit jantung dan pembuluh darah sebanyak $30 \%$ dari total penyakit tidak menular lainnya. Tercatat 17,1 juta orang meninggal di dunia akibat penyakit jantung dan diperkirakan angka ini akan meningkat hingga tahun 2030 menjadi 23,4 juta kematian di dunia (Depkes, 2011).

Data yang diperoleh dari Direktorat Jendral Yanmedik Indonesia pada penelitian tahun 2009 menyatakan bahwa jumlah pasien penyakit jantung yang mengalami rawat inap dan rawat jalan di RS di Indonesia adalah 239.548 jiwa. Kasus terbanyak adalah penyakit iskemik yaitu 110.183 kasus.
Case Fatality Rate (CFR) tertinggi terjadi pada miokard infark akut $(13,49 \%)$ dan kemudian diikuti gagal jantung $(13,42 \%)$ dan penyakit jantung lainnya (13,37\%) (Depkes, 2011).

Berdasarkan data yang diperoleh dari rekam medik RSUD Dr. Moewardi Surakarta diperoleh data prevalensi penderita AMI di ruang ICVCU pada tahun 2010-2011 sebanyak 183 pasien, sedangkan pada tahun 2013-2014 meningkat menjadi 825 pasien sedangkan penderita AMI berulang di Ruang ICVCU pada tanggal 30 November 2015 sampai 13 Desember 2015 sebanyak 11 pasien dari jumlah total pasien AMI yaitu 23 pasien.

Beberapa literatur mengatakan bahwa kadar kolesterol yang tinggi, hipertensi, merokok, latihan fisik, pengaruh suhu dingin, makanan berlemak, stress, dislipidemia, kelebihan berat badan, dan diabetes mellitus dapat menjadi faktor risiko kejadian AMI. Namun, pada saat ini beberapa faktor seperti kebiasaan merokok dan makan-makanan yang mengandung tinggi kolesterol menjadi suatu kebiasaan bagi sebagian warga masyarakat seiring dengan perubahan pola hidup masyarakat. Mungkin oleh alasan tersebut, tidak jarang pasien dengan penyakit kardiovaskuler mengalami serangan jantung berulang. Penelitian terbaru yaitu Triyanta (2011), mengatakan bahwa buruknya kualitas tidur dapat memicu serangan jantung. 
Dari uraian diatas, maka perlu dilakukan penelitian lebih lanjut untuk menguatkan teori yang ada dan perlu usaha untuk mengetahui faktor lain yang mempengaruhi serangan jantung berulang diiringi dengan tingginya prosentase penyakit jantung khususnya AMI baik di lingkup dunia maupun di Indonesia. Oleh karena itu, penulis tertarik untuk melakukan penelitian mengenai faktor terjadinya serangan jantung berulang pada Pasien Acute Miokard Infark (AMI). Berdasarkan prevalensi di RSUD Dr. Moewardi, perlonjakan jumlah pasien AMI yang tajam, dan hampir setengah penderita AMI merupakan AMI berulang, maka peneliti merencanakan untuk mengambil penelitian di Ruang Intensif Cardiovasculer Care Unit (ICVCU) RSUD Dr. Moewardi Surakarta.

\section{METODE PENELITIAN}

penelitian kuantitatif noneksperimental. Rancangan penelitian yang digunakan berupa deskriptif analitik dengan pendekatan metode cross-sectional karena penelitian ini untuk mempelajari dinamika korelasi antara faktor resiko dengan efek, dengan cara observasi atau pengumpulan data sekaligus pada suatu saat. Penelitian ini menggunakan studi retrospektif karena faktor risiko diukur dengan melihat kejadian masa lampau untuk mengetahui ada tidaknya faktor risiko yang dialami.

Pengumpulan

data

menggunakan metode wawancara, dokumentasi, dan angket atau Questionaire yang bertujuan menganalisa variabel bebas dan variabel terikat. Pelaksanaan teknik sampling dalam penelitian ini menggunakan total sampling dan mendapatkan sampel sebesar 26 responden. Analisis data terdiri dari analisis univariat, bivariat, dan multivariat. Analisis Bivariat menggunakan uji Chi Square dan uji Fisher, sedangkan analisis multivariat menggunakan uji regresi logistik.

\section{HASIL PENELITIAN}

\section{Karakteristik responden}

Umur

Tabel 1

Distribusi Frekuensi Responden Berdasarkan Umur

\begin{tabular}{clcc}
\hline Umur & n & $\begin{array}{c}\text { Presentase } \\
(\%)\end{array}$ \\
\hline 1 & 26-45 tahun & 7 & 26,9 \\
2 & $>45$ tahun & 19 & 73,1 \\
\hline \multicolumn{2}{c}{ Total } & 26 & 100 \\
\hline Dari 26 & responden, & usia
\end{tabular}

terbanyak yaitu $>45$ tahun sebesar 19 $(73,1 \%)$.

\section{Jenis Kelamin}

Tabel 2

Distribusi Frekuensi Responden Berdasarkan Jenis Kelamin

\begin{tabular}{llcc}
\hline & $\begin{array}{l}\text { Jenis } \\
\text { Kelamin }\end{array}$ & n & $\begin{array}{c}\text { Presentase } \\
(\boldsymbol{\%})\end{array}$ \\
\hline 1. & Laki-laki & 17 & 65,4 \\
2. & Perempuan & 9 & 34,6 \\
\hline \multicolumn{2}{c}{ Total } & 26 & 100 \\
\hline Dari 26 & responden, & jenis
\end{tabular}
kelamin terbanyak laki-laki sebesar 17 $(65,4 \%)$.

\section{Pekerjaan}

\section{Tabel 3}

Distribusi Frekuensi Responden Berdasarkan Pekerjaan

\begin{tabular}{llcc}
\hline Pekerjaan & n & $\begin{array}{c}\text { Presentase } \\
(\%)\end{array}$ \\
\hline 1. & Wiraswasta & 5 & 19,2 \\
2. & PNS & 2 & 7,7 \\
3. & Petani & 10 & 38,5 \\
4. & Buruh & 4 & 15,4 \\
5. & Tidak Bekerja & 5 & 19,2 \\
\hline & Total & 26 & 100 \\
\hline
\end{tabular}


Dari 26 responden, jenis pekerjaan terbanyak sebagai petani sebesar $10(38,5 \%)$.

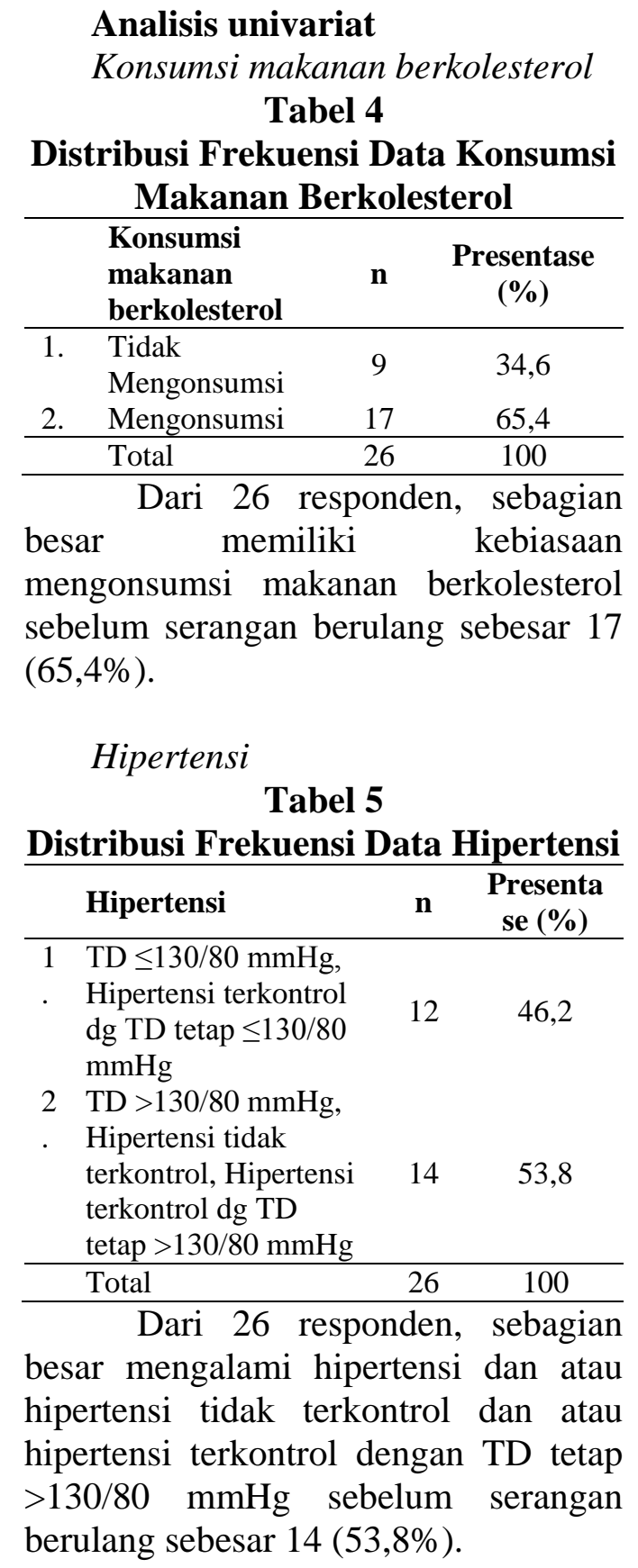

Merokok

Tabel 6

Distribusi Frekuensi Data Merokok

\begin{tabular}{|c|c|c|c|}
\hline & Merokok & $\mathbf{n}$ & Presentase $(\%)$ \\
\hline 1. & $\begin{array}{l}\text { Tidak } \\
\text { Merokok }\end{array}$ & 18 & 69,2 \\
\hline 2. & Merokok & 8 & 30,8 \\
\hline & Total & 26 & 100 \\
\hline
\end{tabular}

besar tidak memiliki kebiasaan merokok sebelum serangan berulang sebesar $18(69,2 \%)$.

Diabetes Mellitus

Tabel 7

Distribusi Frekuensi Data Diabetes Mellitus

\begin{tabular}{|c|c|c|c|}
\hline & Diabetes Mellitus & $\mathbf{n}$ & $\begin{array}{c}\text { Presentase } \\
(\%)\end{array}$ \\
\hline \multirow{3}{*}{$\begin{array}{l}1 . \\
2 .\end{array}$} & $\begin{array}{l}\text { GDS } \leq 200 \mathrm{mg} / \mathrm{dl}, \\
\text { DM terkontrol } \\
\text { dengan GDS tetap } \\
\leq 200 \mathrm{mg} / \mathrm{dl}\end{array}$ & 10 & 38,5 \\
\hline & $\begin{array}{l}\text { GDS > } 200 \mathrm{mg} / \mathrm{dl} \text {, } \\
\text { DM tidak } \\
\text { terkontrol, DM } \\
\text { terkontrol dengan } \\
\text { GDS tetap >200 } \\
\mathrm{mg} / \mathrm{dl}\end{array}$ & 16 & 61,5 \\
\hline & Total & 26 & 100 \\
\hline & $\begin{array}{l}\text { Dari } 26 \text { re } \\
\text { mengalami } \\
\text { terkontrol, DN } \\
\text { tetap > } 20 \\
\text { igan berulang se }\end{array}$ & & $\begin{array}{l}\text { sebagian } \\
\text { atau DM } \\
\text { ol dengan } \\
\text { sebelum } \\
(61,5 \%) \text {. }\end{array}$ \\
\hline
\end{tabular}


Latihan Fisik

Tabel 8

\section{Distribusi Frekuensi Data Latihan} Fisik

\begin{tabular}{|c|c|c|c|}
\hline & Latihan Fisik & $\mathbf{n}$ & $\begin{array}{c}\text { Presenta } \\
\text { se }(\%)\end{array}$ \\
\hline 1. & $\begin{array}{l}\text { Melakukan } \\
\text { latihan fisik } \\
\text { sesuai kriteria } \\
\text { dengan } \\
\text { intensitas baik }\end{array}$ & 12 & 46,2 \\
\hline 2. & $\begin{array}{l}\text { Tidak } \\
\text { melakukan } \\
\text { latihan fisik, } \\
\text { melakukan } \\
\text { latihan fisik } \\
\text { tidak sesuai } \\
\text { kriteria dan } \\
\text { intensitas buruk }\end{array}$ & 14 & 53,8 \\
\hline & Total & 26 & 100 \\
\hline
\end{tabular}

besar tidak memiliki kebiasaan latihan fisik, dan atau melakukan latihan fisik tidak sesuai kriteria dan intensitas buruk sebelum serangan berulang sebesar $14(53,8 \%)$.

Kualitas tidur

Tabel 9

Distribusi Frekuensi Data Kualitas Tidur

\begin{tabular}{llcc}
\hline Kualitas & n & $\begin{array}{c}\text { Presen } \\
\text { tase }\end{array}$ \\
\hline Tidur & $\begin{array}{l}\text { Tidak ada } \\
\text { gangguan } \\
\text { tidur }\end{array}$ & 12 & 46,2 \\
2. & $\begin{array}{l}\text { Ada } \\
\text { gangguan } \\
\text { tidur }\end{array}$ & 14 & 53,8 \\
\hline & Total & 26 & 100 \\
\hline
\end{tabular}

Dari 26 responden, sebagian besar tidak mengalami gangguan tidur sebelum serangan berulang yaitu 14 $(53,8 \%)$.

\section{PEMBAHASAN}

Analisis Bivariat

Konsumsi makanan kolesterol dengan serangan jantung berulang
Tabel 4.10

Konsumsi makanan kolesterol dengan serangan jantung berulang

\begin{tabular}{|c|c|c|c|c|c|c|}
\hline \multirow{2}{*}{\multicolumn{2}{|c|}{$\begin{array}{l}\text { Konsumsi } \\
\text { makanan } \\
\text { kolesterol }\end{array}$}} & \multicolumn{2}{|c|}{ Serangan jantung berulang } & \multirow[b]{2}{*}{$\mathrm{OR}$} & \multirow[b]{2}{*}{$P$} & \multirow[b]{2}{*}{$\begin{array}{c}95 \% \\
\mathrm{CI}\end{array}$} \\
\hline & & $\begin{array}{c}\text { Serangan } \\
\text { kedua }\end{array}$ & $\begin{array}{c}\text { Serangan } \\
\text { ketiga atau } \\
\text { lebih }\end{array}$ & & & \\
\hline \multirow[t]{5}{*}{1} & Tidak & $8(53,3 \%)$ & $1(9,1 \%)$ & \multirow{4}{*}{11,4} & \multirow{4}{*}{0,019} & \multirow{4}{*}{$\begin{array}{c}1,2- \\
113,1\end{array}$} \\
\hline & mengonsumsi & 5,2 & 3,8 & & & \\
\hline & Mengonsumsi & $7(46,7 \%)$ & $10(90,9 \%)$ & & & \\
\hline & & 9,8 & 7,2 & & & \\
\hline & Total & 15 & 11 & & & \\
\hline
\end{tabular}

Pasien dengan serangan jantung ketiga atau lebih sebagian besar memiliki kebiasaan mengonsumsi makanan berkolesterol sejumlah 10 $(90,9 \%)$ dari 26 responden. Hasil analisis chi square menunjukkan terdapat nilai expected yang kurang dari 5, oleh karena itu uji yang dipakai adalah uji alternatifnya, yaitu uji Fisher.

Tabel 4.11.

Uji Fisher Konsumsi Makanan Berlemak

\begin{tabular}{cc}
\hline Konsumsi MakananBerkolesterol & Nilai Exact Sig. (2-sided) \\
\hline Fisher's Exact Test & 0.036 \\
\hline Sumber: Data Primer (Diolah SPSS For Windows Versi 17, Juni 2016)
\end{tabular}

Hasil uji Fisher menunjukkan nilai $p$ value $0,036(<0,05)$ berarti konsumsi kolesterol mempunyai pengaruh yang signifikan dengan serangan jantung berulang dengan nilai OR 11,4 berarti berisiko mengalami serangan jantung berulang sebesar 11,4 kali lebih besar dibandingkan dengan yang tidak mengonsumsi makanan kolesterol dengan nilai $95 \%$ CI sebesar $1,2-113,1$.

Penelitian ini didukung oleh penelitian Dewi (2014), menunjukkan peningkatan trigliserida berpengaruh pada kejadian AMI dengan taraf signifikansi $0,003 \quad(<0,25)$. Apabila seseorang lebih banyak mengonsumsi kalori melebihi kebutuhan tubuh seperti lemak maka kemungkinan menyebabkan peningkatan trigiserida 
(Karyadi, 2006). Trigliserida merupakan salah satu jenis lemak yang berada di dalam darah yang sifatnya merugikan seperti LDL.

Diperkuat juga oleh teori Soeharto (2004), kolesterol dalam zat makanan yang kita makan meningkatkan kadar kolesterol dalam darah, kolesterol berlebih ini akan bereaksi dengan zat-zat lain dan mengendap di dalam pembuluh darah arteri, sehingga menyebabkan penyempitan dan pengerasan yang dikenal sebagai atherosclerosis.

Hipertensi dengan serangan jantung berulang

Tabel 4.12

Hipertensi dengan serangan jantung berulang

\begin{tabular}{|c|c|c|c|c|c|c|}
\hline & \multirow[b]{2}{*}{ Hipertensi } & \multicolumn{2}{|c|}{ Serangan jantung berulang } & \multirow[b]{2}{*}{ OR } & \multirow[b]{2}{*}{$p$} & \multirow[b]{2}{*}{$\begin{array}{c}95 \% \\
\mathrm{CI}\end{array}$} \\
\hline & & $\begin{array}{c}\text { Serangan } \\
\text { kedua }\end{array}$ & $\begin{array}{c}\text { Serangan } \\
\text { ketiga atau } \\
\text { lebih }\end{array}$ & & & \\
\hline 1 & $\begin{array}{l}\mathrm{TD} \leq 130 / 80 \\
\text { mmHg, Hipertensi } \\
\text { terkontroldg TD } \\
\text { tetap } \leq 130 / 80 \\
\mathrm{mmHg}\end{array}$ & $\begin{array}{c}10(66,7 \%) \\
6,9\end{array}$ & $\begin{array}{c}2(18,2 \%) \\
5,1\end{array}$ & & & \\
\hline 2 & $\begin{array}{l}\text { TD }>130 / 80 \\
\text { mmHg, Hipertensi } \\
\text { tidak terkontrol, } \\
\text { Hipertensi } \\
\text { terkontroldg TD } \\
\text { tetap }>130 / 80 \\
\text { mmHg }\end{array}$ & $\begin{array}{c}5(33,3 \%) \\
8,1\end{array}$ & $\begin{array}{c}9(81,8 \%) \\
5,9\end{array}$ & 9 & $\begin{array}{c}0,01 \\
4\end{array}$ & $\begin{array}{l}1,4- \\
58,4\end{array}$ \\
\hline
\end{tabular}
\begin{tabular}{c}
\hline Sumber: Data Primer (Diolah SPSS For Windows Versi 17, Juni 2016) \\
Pasien yang mengalami
\end{tabular} serangan jantung ketiga atau lebih sebagian besar mengalami hipertensi sejumlah $9(81,8 \%)$ dari 26 responden. Hasil analisis Chi Square menunjukkan nilai $\mathrm{p}$ value $0,014(<0,05)$ berarti hipertensi mempunyai pengaruh yang signifikan dengan serangan jantung berulang dengan nilai OR sebesar 9 berarti berisiko mengalami serangan jantung berulang sebesar 9 kali lebih besar dibandingkan dengan yang tidak hipertensi dengan nilai 95\% CI sebesar 1,4-58,4.
Penelitian terdahulu yang mendukung adalah penelitian yang dilakukan Dewi (2014), didapatkan nilai $p=0,008$ dan $\alpha=0,25$ yang menunjukkan bahwa ada hubungan yang signifikan antara hipertensi dengan terjadinya serangan jantung AMI. Tekanan darah yang tinggi secara terus-menerus menambah beban pembuluh arteri. Arteri mengalami pengerasan, menjadi tebal dan kaku, sehingga mengurangi elastisitasnya. Tekanan darah yang terus-menerus tinggi dapat pula menyebabkan dinding arteri rusak atau luka dan mendorong proses terbentuknya plak pada arteri koroner (ateriosklerosis) (Soeharto, 2004).

Merokok dengan serangan jantung berulang

Tabel 4.13

Merokok dengan serangan jantung berulang

\begin{tabular}{|c|c|c|c|c|c|c|}
\hline \multirow{2}{*}{\multicolumn{2}{|c|}{ Merokok }} & \multicolumn{2}{|c|}{ Serangan jantung berulang } & \multirow[b]{2}{*}{ OR } & \multirow[b]{2}{*}{$p$} & \multirow[b]{2}{*}{$\begin{array}{r}95 \% \\
\mathrm{CI}\end{array}$} \\
\hline & & $\begin{array}{c}\text { Serangan } \\
\text { kedua }\end{array}$ & $\begin{array}{c}\text { Serangan } \\
\text { ketiga atau } \\
\text { lebih }\end{array}$ & & & \\
\hline \multirow[t]{2}{*}{1} & Tidak & $13(86,7 \%)$ & $5(45,5 \%)$ & \multirow{4}{*}{7,8} & \multirow{4}{*}{0,024} & \multirow{4}{*}{$\begin{array}{l}1,2-2 \\
52,4\end{array}$} \\
\hline & merokok & 10,4 & 7,6 & & & \\
\hline \multirow[t]{3}{*}{2} & Merokok & $2(13,3 \%)$ & $6(54,5 \%)$ & & & \\
\hline & & 4,6 & 3,4 & & & \\
\hline & Total & 15 & 11 & & & \\
\hline
\end{tabular}

Sumber: Data Primer (Diolah SPSS For Windows Versi 17, Juni 2016)

Pasien yang mengalami serangan jantung ketiga atau lebih sebagian besar memiliki kebiasaan merokok sejumlah $6(54,5 \%)$ dari 26 responden.

Tabel 4.14.

Uji Fisher Merokok

\begin{tabular}{cc}
\hline Merokok & Nilai Exact Sig. (2-sided) \\
\hline Fisher's Exact Test & 0.038 \\
\hline
\end{tabular}

Sumber: Data Primer (Diolah SPSS For Windows Versi 17, Juni 2016)

Hasil uji Fisher menunjukkan nilai $\mathrm{p}$ value $0,038(<0,05)$ berarti merokok mempunyai pengaruh yang signifikan dengan serangan jantung berulang dengan nilai OR sebesar 7,8 berarti berisiko serangan jantung 
berulang sebesar 7,8 kali lebih besar dibandingkan dengan yang tidak merokok dengan nilai $95 \%$ CI sebesar $1,2-52,4$. Penelitian terdahulu yang mendukung adalah penelitian yang dilakukan Kalalo,dkk (2013), didapatkan nilai $p=0,000$ dan $\alpha=0,05$ yang menunjukkan bahwa ada hubungan yang signifikan antara gaya hidup merokok dengan terjadinya serangan jantung AMI. Menurut penelitian Fonarow G, dari school of medicine at the University of California (2008), seseorang dapat mengalami serangan jantung berulang tanpa faktor risiko lain jika seseorang tersebut merokok. Selain itu, menurut penelitian Framingham Heart Study dalam Soeharto (2004) menemukan bahwa merokok menurunkan kadar kolesterol baik yaitu HDL. Dimana HDL ini memiliki fungsi untuk pelindung terhadap arteri koroner (Muttaqin, 2009).

Diabetes mellitus dengan serangan jantung berulang

\begin{tabular}{|c|c|c|c|c|c|c|}
\hline & \multicolumn{6}{|c|}{$\begin{array}{c}\text { Tabel } 4.15 \\
\text { Diabetes mellitus dengan serangan jantung berulang }\end{array}$} \\
\hline & \multirow[b]{2}{*}{ Diabetes mellitus } & \multicolumn{2}{|c|}{$\begin{array}{l}\text { Serangan jantung } \\
\text { berulang }\end{array}$} & \multirow[b]{2}{*}{ OR } & \multirow[b]{2}{*}{$p$} & \multirow{2}{*}{$\begin{array}{c}95 \% \\
\mathrm{CI}\end{array}$} \\
\hline & & $\begin{array}{l}\text { Serangan } \\
\text { kedua }\end{array}$ & $\begin{array}{c}\text { Serangan } \\
\text { ketiga atau } \\
\text { lebih }\end{array}$ & & & \\
\hline 1 & $\begin{array}{l}\text { GDS } \leq 200 \mathrm{mg} / \mathrm{dl}, \\
\text { DM terkontrol dg } \\
\text { GDS tetap } \leq 200 \\
\mathrm{mg} / \mathrm{dl}\end{array}$ & $\begin{array}{c}9(60,0 \%) \\
5,8\end{array}$ & $\begin{array}{c}1(9,1 \%) \\
4,2\end{array}$ & & & \\
\hline 2 & $\begin{array}{l}\text { GDS }>200 \\
\text { mg/dl, DM tidak } \\
\text { terkontrol, DM } \\
\text { terkontrol dg } \\
\text { GDS tetap }>200 \\
\mathrm{mg} / \mathrm{dl}\end{array}$ & $\begin{array}{c}6(40,0 \%) \\
9,2\end{array}$ & $\begin{array}{c}10(90,9 \%) \\
6,8\end{array}$ & 15,0 & 0,08 & $\begin{array}{c}1,5- \\
149, \\
7\end{array}$ \\
\hline & Total & 15 & 11 & 26 & & \\
\hline
\end{tabular}

Pasien yang mengalami serangan jantung ketiga atau lebih sebagian besar mengalami DM sejumlah $10 \quad(90,9 \%)$ dari 26 responden.
Tabel 4.16

Uji Fisher Diabetes Mellitus

\begin{tabular}{cc}
\hline Diabetes mellitus & Nilai Exact Sig. (2-sided) \\
\hline Fisher's Exact Test & 0.014 \\
\hline Sumber: Data Primer (Diolah SPSS For Windows Versi 17, Juni 2016)
\end{tabular}

Hasil uji Fisher menunjukkan nilai $\mathrm{p}$ value $0,014(<0,05)$ berarti $\mathrm{DM}$ mempunyai pengaruh yang signifikan dengan serangan jantung berulang dengan nilai OR sebesar 15,0 berarti berisiko mengalami serangan jantung berulang sebesar 15,0 kali lebih besar dibandingkan dengan yang tidak mengalami DM dengan nilai 95\% CI sebesar 1,5-149,7. Penelitian terdahulu yang mendukung adalah penelitian yang dilakukan Delima (2009), didapatkan nilai OR prevalen adjusted 4,06 yang menunjukkan bahwa diabetes mellitus merupakan faktor determinan penyakit jantung koroner. Bila kadar gula darah selalu tinggi, kerusakan dapat terjadi pada pembuluh darah yang kecil yang membawa oksigen ke jaringan tubuh. Arteri kecil atau disebut juga Artherioles akan menjadi penuh plak. Kerusakan tersebut dapat terjadi di berbagai bagian tubuh sehingga bagian tersebut tidak menerima oksigen secara penuh. Kekurangan oksigen secara kronis di atas dapat menyebabkan kerusakan bagian-bagian organ secara bertahap (Soeharto, 2004).

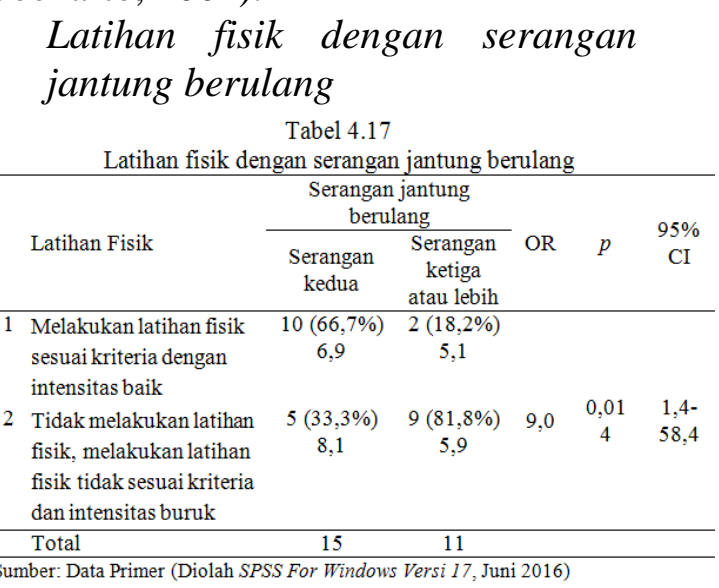


Pasien yang mengalami serangan jantung kedua sebagian besar memiliki kebiasaan latihan fisik sejumlah $10 \quad(66,7 \%)$ dari 26 responden. Sedangkan responden yang mengalami serangan jantung ketiga atau lebih sebagian besar tidak memiliki kebiasaan latihan fisik atau melakukan latihan fisik tidak sesuai kriteria sejumlah $9(81,8 \%)$ dari 26 responden. Hasil analisis chi square menunjukkan nilai $\mathrm{p}$ value 0,014 (< $0,05)$ berarti latihan fisik mempunyai pengaruh yang signifikan dengan serangan jantung berulang dengan nilai OR sebesar 9 berarti tidak latihan fisik atau melakukan latihan fisik tidak sesuai kriteria berisiko mengalami serangan jantung berulang sebesar 9 kali lebih besar dibandingkan dengan yang melakukan latihan fisik sesuai kriteria dengan nilai 95\% CI sebesar 1,4-58,4.

Penelitian terdahulu yang mendukung adalah penelitian yang dilakukan Salim (2013), didapatkan hasil bahwa olahraga dapat menjadi faktor resiko kejadian penyakit jantung koroner, dimana orang yang kurang berolahraga memiliki resiko 2 kali lebih besar mengalami penyakit jantung koroner. Menurut Kushartanti (2000) olahraga kuratif pada penderita jantung koroner dimaksudkan untuk memperlebar pembuluh darah koroner, menambah kapilarisasi jantung dan memperbaiki profil lipid, terutama menurunkan LDL kolesterol dan meningkatkan HDL kolesterol.

Kualitas tidur dengan serangan jantung berulang

Tabel 4.18

Kualitas tidur dengan serangan jantung berulang

\begin{tabular}{|c|c|c|c|c|c|c|}
\hline & \multirow[b]{2}{*}{ Kualitas tidur } & \multicolumn{2}{|c|}{ Serangan jantung berulang } & \multirow[b]{2}{*}{ OR } & \multirow[b]{2}{*}{$p$} & \multirow[b]{2}{*}{$\begin{array}{r}95 \% \\
\mathrm{CI}\end{array}$} \\
\hline & & $\begin{array}{c}\text { Serangan } \\
\text { kedua }\end{array}$ & $\begin{array}{c}\text { Serangan } \\
\text { ketiga atau } \\
\text { lebih }\end{array}$ & & & \\
\hline 1 & Tidakada & $10(66,7 \%)$ & $2(18,2 \%)$ & \multirow{4}{*}{9,0} & \multirow{4}{*}{0,014} & \\
\hline & gangguan tidur & 6,9 & 5,1 & & & $1,4-$ \\
\hline \multirow[t]{3}{*}{2} & Ada gangguan & $5(33,3 \%)$ & $9(81,8 \%)$ & & & 58,4 \\
\hline & tidur & 8,1 & 5,9 & & & \\
\hline & Total & 15 & 11 & & & \\
\hline
\end{tabular}

Pasien yang mengalami serangan jantung kedua sebagian besar tidak mengalami gangguan tidur sejumlah $10 \quad(66,7 \%)$ dari 26 responden. Sedangkan responden yang mengalami serangan jantung ketiga atau lebih sebagian besar mengalami gangguan tidur sejumlah $9(81,8 \%)$ dari 26 responden. Hasil analisis Chi Square menunjukkan nilai $\mathrm{p}$ value $0,014(<0,05)$ berarti kualitas tidur mempunyai pengaruh yang signifikan dengan serangan jantung berulang dengan nilai OR sebesar 9 berarti gangguan tidur berisiko menyebabkan serangan jantung berulang sebesar 9 kali lebih besar dibandingkan dengan yang tidak mengalami gangguan tidur dengan nilai $95 \%$ CI sebesar 1,4-58,4.

Penelitian terdahulu yang mendukung adalah penelitian yang dilakukan Triyanta (2014), didapatkan nilai $r$ hitung $<\mathrm{r}$ tabel $(0,668>0,339)$ yang menunjukkan bahwa ada hubungan yang signifikan antara kualitas tidur dengan denyut jantung pada pasien infark miokard. Hal ini mendukung teori Mc Cance dan Huether (2006, dalam Potter, 2010) Seseorang yang kurang tidur maka akan meningkatkan RAS (Reticular activating system), bila RAS meningkat akan meningkatkan emosi seseorang yang akhirnya hormon menstimulasi kontraksi jantung dan akhirnya denyut jantung meningkat (takikardia). Oleh karena itu, semakin sering orang mengalami gangguan tidur atau kurang tidur, maka RAS akan selalu meningkat dan takikardi sering terjadi, maka kemungkinan terjadinya serangan jantung berulang semakin besar. 


\section{Analisis multivariat}

\section{Seleksi Bivariat}

\begin{tabular}{ccccccc}
\multicolumn{7}{c}{ Tabel 4.19 Variabel Kandidat Multivariat } \\
\hline No & Variabel & B & Wald & P value & OR & $95 \%$ \\
\hline 1. & Kolesterol & $-2,436$ & 4,339 & 0,037 & 0.088 & 0,01 \\
2. Hipertensi & $-2,197$ & 5,299 & 0,021 & 0,111 & 0,0 \\
& & & & & & 0,7 \\
3. Merokok & -2.054 & 4,472 & 0,034 & 0,128 & 0,0 \\
4. DM & $-2,708$ & 5,323 & 0,021 & 0,067 & 0,01 \\
5. Latihan Fisik & $-2,197$ & 5,299 & 0,021 & 0,111 & 0,0 \\
& & & & & & 0,7 \\
6 & Kualitas Tidur & $-2,197$ & 5,299 & 0,021 & 0,111 & 0,0 \\
& & & & & 0,7 \\
\hline Sumber: Data Primer (Diolah SPSS For Windows Versi 17, Juni 2016) &
\end{tabular}

Tabel 4.19 menunjukkan dalam seleksi kandidat pada penelitian ini yang menghasilkan $p$ value $<0,25$ antara lain variabel konsumsi kolesterol, hipertensi, merokok, diabetes mellitus, latihan fisik dan kualitas tidur.

\section{Pemodelan Multivariat}

Tabel 4.20 Analisis Multivariat Step 1

\begin{tabular}{llccccc}
\hline No & Variabel & B & Wald & P value & OR & $95 \%$ \\
\hline 1. & Kolesterol & -2.056 & 1.342 & 0.247 & 0.128 & 0,1 \\
& & & & & & 4. \\
2. & Hipertensi & -4.998 & 2.195 & 0.138 & 0.007 & 0,1 \\
& & & & & & 5. \\
3. & Merokok & -2.697 & 1.500 & 0.221 & 0.067 & 0,1 \\
4. DM & -2.463 & 2.082 & 0.149 & 0.085 & 0,1 \\
& & & & & & 2. \\
5. Latihan Fisik & -3.723 & 2.010 & 0.156 & 0.024 & 0,1 \\
& & & & & 4. \\
6. Kualitas Tidur & -2.270 & 1.170 & $0.279^{*}$ & 0.103 & 0,1 \\
& & & & & & 6. \\
\hline
\end{tabular}

Sumber: Data Primer (Diolah SPSS For Windows Versi 17, Juni 2016) Keterangan * memiliki $p$ value terbesar dan hanus dikeluarkan

Tabel 4.20 menunjukkan bahwa variabel kualitas tidur memiliki $p$ value terbesar yaitu 0,279 ( $p$ value $>$ $0,25)$ sehingga harus dikeluarkan untuk menentukan variabel yang menjadi faktor dominan.

Tabel 4.21 Analisis Multivariat Step 2

\begin{tabular}{ccccccc}
\hline No & Variabel & B & Wald & P value & OR & $95 \%$ CI \\
\hline 1. & Kolesterol & -2.803 & 2.679 & 0.102 & 0.061 & $0,002-$ \\
& & & & & & 1.739 \\
2. & Hipertensi & -4.245 & 2.350 & 0.125 & 0.014 & $0,000-$ \\
& & & & & & 3.264 \\
3. & Merokok & -2.901 & 1.412 & $0.255^{*}$ & 0.055 & $0,000-$ \\
& & & & & & 6.579 \\
4. & DM & -2.521 & 2.096 & 0.148 & 0.080 & $0,003-$ \\
& & & & & 2.440 \\
5. & Latihan Fisik & -2.618 & 2.204 & 0.138 & 0.073 & $0,002-$ \\
& & & & & & 2.313 \\
\hline Sumber: Data Primer (Diolah SPSS For Windows Versi W Juni 2016) &
\end{tabular}

Keterangan * - memiliki $p$ value terbesar dan hanus dikeluarkan.
Tabel 4.21 menunjukkan bahwa variabel merokok memiliki $p$ value terbesar yaitu 0,255 ( $p$ value $>0,25$ ) sehingga harus dikeluarkan untuk menentukan variabel yang menjadi faktor dominan.

\begin{tabular}{lcccccc}
\multicolumn{7}{c}{ Tabel 4.22 Analisis Multivariat Step 3 } \\
\hline No & Variabel & B & Wald & Pvalue & OR & $95 \% \mathrm{CI}$ \\
\hline 1. & Kolesterol & -2.950 & 2.620 & 0.105 & 0.052 & $0,001-$ \\
& & & & & & 1.862 \\
2. Hipertensi & -2.739 & 3.003 & 0.083 & 0.065 & $0.003-$ \\
& & & & & & 1.432 \\
4. DM & -3.358 & 3.914 & 0.048 & 0.035 & $0,001-$ \\
& & & & & 0.969 \\
5. & Latihan Fisik & -2.739 & 3.003 & 0.083 & 0.065 & $0,003-$ \\
& & & & & & 1.432 \\
\hline
\end{tabular}

Sumber: Data Primer (Diolah SPSS For Windows Versi 17, Juni 2016)

Tabel 4.22 menunjukkan bahwa faktor hipertensi dan latihan fisik merupakan variabel dominan yang mempengaruhi kejadian serangan jantung berulang yaitu 0,065 kali lebih besar pengaruhnya terhadap kejadian serangan jantung berulang.

\section{Keterbatasan penelitian}

1. Variabel konsumsi makanan berlemak kurang didukung dengan hasil pemeriksaan laboratorium kolesterol responden karena tidak semua pasien dengan AMI mendapat program pemeriksaan kadar kolesterol dari rumah sakit.

2. Penulis tidak mampu melakukan observasi secara menyeluruh setiap hari selama 1 bulan terakhir sehingga ada beberapa sampel yang seharusnya masuk kriteria inklusi tetapi tidak dapat diobservasi, hal ini dikarenakan peneliti tidak menggunakan enumerator. 


\section{KESIMPULAN DAN SARAN KESIMPULAN}

1.1 Konsumsi makanan bekolesterol merupakan faktor terjadinya serangan jantung berulang $(\mathrm{p}=$ $0.039)$ dengan besar resiko 11,4 kali lebih besar

1.2 Hipertensi merupakan faktor terjadinya serangan jantung berulang $(\mathrm{p}=0,014)$ dengan besar resiko 9 kali lebih besar

1.3 Merokok merupakan faktor terjadinya serangan jantung berulang $(\mathrm{p}=0,038)$ dengan besar resiko 7,8 kali lebih besar

1.4 Diabetes mellitus merupakan faktor terjadinya serangan jantung berulang $(\mathrm{p}=0,014)$ dengan besar resiko 15 kali lebih besar

1.5 Latihan fisik bukan merupakan merupakan faktor terjadinya serangan jantung berulang $(\mathrm{p}=$ 0,014) dengan besar resiko 9 kali lebih besar

1.6 Kualitas tidur merupakan faktor terjadinya serangan jantung berulang $(p=0,014)$ dengan besar resiko 9 kali lebih besar

1.7 Faktor resiko dominan kejadian serangan jantung berulang adalah hipertensi dan latihan fisik $(\mathrm{OR}=$ $0,065)$

\section{SARAN}

1.8 Bagi responden

Perlu diberikan sosialisasi kepada responden tentang faktor resiko yang mempengaruhi kejadian serangan jantung berulang sehingga responden dapat melakukan pencegahan

1.9 Tenaga kesehatan dan rekam medis rumah sakit

Adanya pendidikan kesehatan ditujukan kepada pasien yang sudah diperbolehkan pulang mengenai asupan makanan dan hal apa saja yang diperbolehkan dan tidak diperbolehkan untuk dilakukan agar tidak terjadi kekambuhan.

1.10Bagi peneliti selanjutnya

Sebaiknya meneliti lebih banyak faktor resiko seperti obesitas, jenis kelamin, stress terhadap kejadian serangan jantung berulang AMI. Selain itu, sebaiknya responden yang diteliti mencakup semua umur, dan disarankan menggunakan kelompok kontrol sehingga diketahui seberapa besar resiko dengan faktor dibanding yang tidak ada faktor risiko.

\section{DAFTAR RUJUKAN}

Dewi, Mentari Rosriyana. (2014). Faktor-faktor dominan sindrom metabolik yang berhubungan dengan kejadian akut Miokard Infark di Ruang ICVCU RSUD Dr.Moewardi Surakarta Tahun 2014. Tersedia di https://www.google.co.id/url\&s ource=web\%2Fdownload.portal garuda diunduh pada 8 Januari 2016

Fonarrow G. (2008). Risk of Heart Failure and Death After Prolonged Smoking Cessation: Role of Amount and Duration of Prior Smoking. Tersedia di http://www.ncbi.nlm.nih.gov/pu bmed/2603853, diunduh pada 10 Januari 2016

Karyadi. (2006). Hidup Bersama Penyakit Hipertensi, Asam Urat, Jantung Koroner. Jakarta: PT Intisari Mediatama

Kushartanti. (2000). Kesehatan Olahraga Kuratif. Yogyakarta: FIK UNY

Muttaqin, A.(2009). Asuhan Keperawatan Klien dengan 
Gangguan

Kardiovaskular.

Salemba Medika
Sistem Soeharto, Iman. (2004). Serangan

Jakarta: Jantung dan Stroke. Jakarta: Gramedia Pustaka Utama

Potter, Patricia A., Anne G. Perry. Triyanta. (2011). Hubungan antara (2010). Fundamental Keperawatan. Jakarta: Salemba Kualitas Tidur dengan Denyut Jantung Dilihat dari Gambaran Medika

Rekam Medik RSUD Dr.Moewardi EKG pada Pasien Infark Miokard di Ruang ICVCU Surakarta. (2015). Laporan RSUD Dr Moewardi Surakarta

Pasien 